\title{
REEVALUATING ALTERNATIVE MEASURES OF INDUSTRIAL DIVERSITY AS INDICATORS OF REGIONAL CYCLICAL VARIATIONS
}

\author{
Bruce D. Wundt*
}

\begin{abstract}
This paper examines the relationship between industrial diversity and regional cyclical instability in a new setting by focusing on detailed information of one region over time. It compares the ability of various measures of regional diversification to explain historical employment variations in manufacturing employment in the state of Connecticut between 1964 and 1983 at both the 2-digit and 3-digit SIC levels. This study demonstrates that the portfolio variance is an effective yardstick for tracking cyclical instability and provides policymakers with a tool to feasibly approach the problem of instability in regions.
\end{abstract}

\section{INTRODUCTION}

Studying the relationship between regional cyclical stability and economic diversity has long been a popular course of inquiry in urban and regional economics. A review of nearly 60 years of research reveals that a variety of definitions and methodological approaches have been employed to define regions and regional diversity. Most analyses have explored this relationship based on a cross section of cities or MSAs at an aggregated 1- or 2-digit SIC level of economic detail. In the broadest sense, diversity has meant the presence of many industries, including an implied balance of industries in a region (equal distribution standard) or one that mirrors the national economy (national average standard). Since durable goods tend to possess a higher income-demand elasticity than nondurables, gauging diversity based on the extent of durables' production has also been a widely employed criterion (percent durables standard). More recently, the entropy index and portfolio variance have been introduced as new tools to reexamine this enduring question. Due to the cyclical nature of the manufacturing sector and since regional policymakers are often concerned with its instability, manufacturing employment is the variable most often selected to gauge cyclical sensitivity in regions. ${ }^{1}$

While empirical results have not been without qualification, there is enough evidence to suggest that industrial composition is one important element influencing economic fluctuations in regions. Yet, despite the evidence, there remains dis-

\footnotetext{
*Department of Economics and Director of Graduate Studies, Bamey School of Business and Public Administration, University of Hartford, West Hartford, Connecticut.
} 
agreement among researchers on the potential benefits to a region from diversification. Given the various approaches and questionable standards employed to explore the stability/diversity relationship, this result should not be surprising. For example, it is conceptually and practically implausible to expect a region to possess the same interindustry linkages, input, output, or spatial endowments as the national average standard. A region's industrial structure cannot be expected to mirror that of the national economy. Even less appropriate is the equal-weight standard, which lacks a systematic approach to regions and regional growth. This concept assumes that the presence of industries, rather than any objective characteristic such as historical instability, is a more relevant indicator of the degree of regional economic fluctuation. (The same criticism applies to the recently employed entropy measure.) While the notion that a high concentration of durables production in a region promotes instability has much empirical support, it is erroneous to conclude that all durable goods industries behave similarly, or that the cyclical behavior of individual durable goods industries is concomitant even with that of the broader group to which they belong. ${ }^{2}$

There is also a practical side to this question that is often of great concern to regional policymakers, one that has largely been ignored in the previous research. The ultimate goal in understanding the diversity/stability relationship is to prescribe a course of action for regions, so that some degree of the instability they experience may be reduced. Unfortunately, given the variety of research approaches, the benefit of recognizing the influence of industrial composition on stability is limited if a policy promoting stability does not result, especially if a policy cannot be prescribed for a particular region. This lack of policy relevance may help explain the divergence of opinion on the significance of diversification in regional economic stability and is likely the result of the approaches taken to study this very issue. ${ }^{3}$

\section{PURPOSE}

Focusing on the industrial composition of a cross section of narrowly defined regions at a highly aggregated level and employing diversification measures often of questionable economic logic do not provide much guidance to policymakers whose goal is to reduce economic instability in their regions.

It is the general intent of this paper to reexamine the relationship between regional economic stability and industrial composition. However, the approach taken here differs in a number of ways from the previous research. Viewing this question from the policymaker's prospective of promoting stability is of paramount interest. Perhaps by focusing on a more detailed level of region- 
specific information over time, a better understanding of the impact that specific industries have on a particular region's economic stability may result. Based on this approach, the results suggest that the portfolio variance may provide a better measure of tracking regional instability than the traditional standards that have been employed for this purpose. It also provides a technique to assist policymakers in identifying industries that tend to promote stability in their regions, which would have positive implications for policy. While an examination of the portfolio variance is beyond the immediate scope of this paper, it may also provide the basis for an industrial expansion model for feasibly addressing the question of reducing instability in regions. For this study, Connecticut is selected as the state for analysis with the focus on a detailed breakdown of its manufacturing sector into 81 industries. The state's policymakers are addressing the related issues of formulating policies to encourage growth in manufacturing and to assist this sector in its transition from defense dependency to one more diversified in its production of goods and services. Policy decisions will affect both the level and composition of industries in the state. ${ }^{4}$

\section{EMPIRICAL ANALYSIS}

The first part of the empirical analysis involves comparing the ability of the various yardsticks of economic diversity to measure regional instability based on the framework described above. The measure that will serve as the indicator of cyclical sensitivity is manufacturing employment between 1964 and $1983 .^{5}$ The first step in this analysis is to develop an index of variability for total manufacturing employment. Since explaining cyclical behavior is the primary focus, each industry and total manufacturing employment were detrended by a log-linear equation of the form:

$$
\ln _{\mathrm{y}}=\mathrm{a}+\mathrm{bt}
$$

where $\mathrm{ln}_{\mathrm{y}}$ is the natural $\log$ of employment, $\mathrm{t}$ is a time index, and $\mathrm{a}$ and $\mathrm{b}$ are parameters to be estimated. A cyclical variability index in total manufacturing employment for each year $\left(\mathrm{CVI}_{\mathfrak{t}}\right)$ is given by the equation:

$$
C V I_{t}=\frac{\left(Y_{t}-\hat{Y}_{t}\right)}{\bar{Y}}
$$


where $Y_{t}$, is actual employment in year $\mathrm{t}, \hat{Y}_{t}$ is estimated trend employment in year t, and $\bar{Y}$ is average manufacturing employment between 1964 and $1983 .{ }^{6}$

Equal Distribution Index: To calculate equal distribution, national average, and entropy indices, it was necessary to calculate the employment shares for each of the 81 manufacturing industries. Employment in every industry was divided by total annual manufacturing employment for each of the 20 years. The equal distribution index (EDI) is given by:

$$
E D I_{t}=\frac{\sum_{l=1}^{81}\left|x_{i, t}^{R}-1 / N\right|}{\operatorname{MAX} \sum_{i=1}^{81}\left|x_{i, t}^{R}-1 / N\right|}
$$

where $\mathrm{N}$ (the number of industries) $=81, \mathrm{t}$ represents years from 1964 to $1983, x_{i, t}^{R}$ is the region's employment share in industry $i$ in year $t$, and $1 / N$ is the equal distribution share for each industry $(1 / \mathrm{N}=1 / 81=0.0123)$. The lower limit of zero implies perfect distribution $\left(x_{i, t}^{R}=1 / \mathrm{N}\right)$; the upper limit of 1.975 implies perfect specialization. Normalizing by 1.975 makes one the maximum value the index can assume.

National Average Index: To construct the national average index (NAI), the corresponding national shares of the 81 industries were calculated in the manner described above. The index is given by:

$$
N A I_{t}=\frac{\sum_{l=1}^{81}\left|x_{i, t}^{R}-x_{i, t}^{N A}\right|}{\operatorname{MAX} \sum_{i=1}^{81}\left|x_{i, t}^{R}-x_{i, t}^{N A}\right|}
$$

where $\mathrm{N}, \mathrm{t}$, and $x_{i, t}^{R}$ are the same as above, and $x_{i, t}^{N A}$ is the national employment share in industry $\mathrm{i}$ in year $\mathrm{t}$. The index equals zero if each state industry share equals its national counterpart. The greater the deviations from the national shares, the greater the index value. As specialization increases, the maximum value the denominator can assume is two, and the index value is one. 
Percent Durables: The third measure is the percentage of manufacturing employment devoted to durable goods production. Before an index is developed, a definition of durables must first be addressed; that is, should the focus be on employment in the manufacture of producers' durables, consumers' durables, durable goods as a whole, or on the distinction between producers' goods and consumers' goods? This question has been answered differently by various researchers. ${ }^{7}$ For this study, the relationship among cyclical employment behavior and durables as a whole and producers' durables and consumers' durables was examined. A description of the procedure used to separate producers' and consumers' durables is given in Appendix 1. The percent durables index is given by:

$$
\mathrm{DUR}_{\mathrm{t}}, \mathrm{PD}_{\mathrm{t}}, \mathrm{CD}_{\mathrm{t}}=(\mathrm{e} / \mathrm{TME})_{\mathrm{t}}
$$

where $T M E_{t}$ is total manufacturing employment in year $t, e_{t}$ is employment in durables as a whole for index $\mathrm{DUR}_{\mathfrak{t}}$, the estimated employment devoted to producers' durables for index $\mathrm{PD}_{\mathfrak{t}}$, and estimated employment devoted to consumers' durables for index $\mathrm{CD}_{\mathrm{t}}$.

Entropy Index: The application of the entropy measure is relatively new to the study of diversification in regional economics (see Hackbart and Anderson 1975). Conceptually similar to the equal distribution measure, it is given by:

$$
E N T_{t}=\left\{c \sum_{i=1}^{81}(-) x_{i, t}^{R} \log x_{i, t}^{R} / M A X c \sum_{i=1}^{81}(-) x_{i, t}^{R} \log x_{i, t}^{R}\right.
$$

where $c$ is an arbitrary constant $(c=1)$. If a region has complete specialization in one industry, the entropy index is zero (since $\ln 1=0$ ). If employment is uniformly distributed among industries, it reaches its maximum value. With 81 sectors, the maximum is 4.378, and the upper limit of the index is one.

Portfolio Variance Measure of Diversification: The portfolio variance was introduced to the problem of regional instability by Conroy (1975). A conceptual advantage of this approach is its ability to account for both individual industry and interindustry employment variations. The portfolio variance measure is given by:

$$
P O R T_{t}=x_{t} V x^{\prime}{ }_{t}
$$

where $X_{t}$ is a row vector $(1 \times 81)$ of industry employment shares in year $t, V$ is the variance/covariance matrix $(81 \times 81)$ based on detrended industry employment, 
and $X^{\prime}{ }_{t}$ is a column vector $(81 \times 1)$ of employment shares. The elements along the main diagonal of $\mathrm{V}$ are the detrended industry employment variances, and the off-diagonal elements of $\mathrm{V}$ are the (6480) interindustry variances or covariance terms.

\section{EMPIRICAL RESULTS}

The cyclical variability index for the state of Connecticut was regressed against each of the diversity measures. The results are given in Table 1 . The signs of these variables in each equation indicate that increased specialization increases cyclical instability. With the exception of the national average and consumers' durables indices, each measure is significant in explaining cyclical employment behavior.

TABLE 1

Regression Results of Diversity Measures in Connecticut (3-digit) (Dependent variable in each equation is CVI)

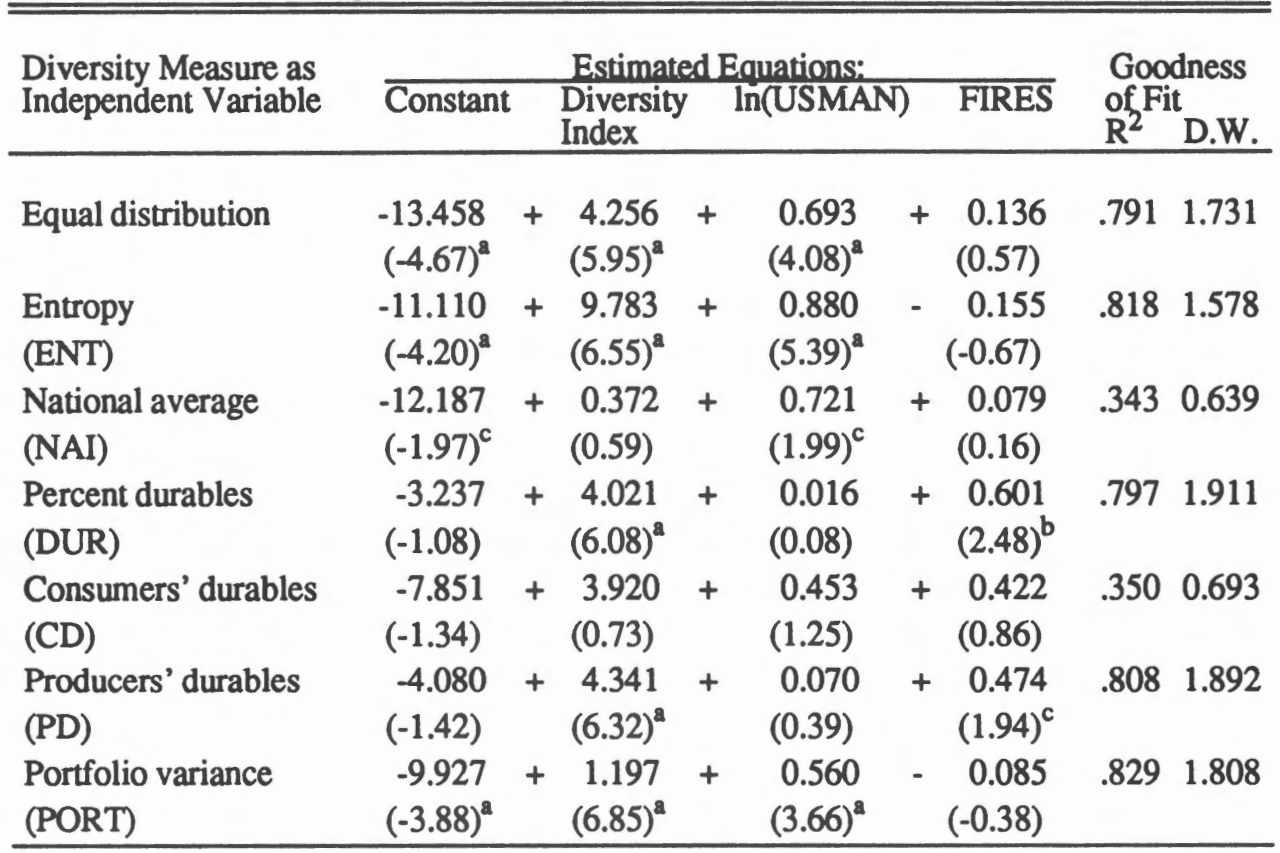

Note: t-statistics are in parentheses below coefficients. $R^{2}$ are adjusted values.

${ }_{b}^{a}$ Significant at .01 level

b Significant at .05 level

${ }^{c}$ Significant at .10 level 
Two other variables are included in each equation. To estimate the impact of business cycle effects on the index, the natural log of manufacturing employment at the national level [In(USMAN)] is included. Its influence, as expected, is positive, and it is generally significant in explaining state cyclical employment variations. To estimate the impact of employment in certain nonmanufacturing industries, a variable (FIRES) representing detrended cyclical employment in the finance, insurance and real estate, and services groups was also included. If the cyclical behavior of this combined group moves counter to that of manufacturing employment, as might be hypothesized, this tendency would offset variations in the index of cyclical employment, which was the case in only two of the estimated equations. Given the significance levels of this variable and the signs of the coefficients in the equations, it cannot be concluded that cyclical behavior in these industries serves to offset cyclical employment in the state's manufacturing sector.

TABLE 2

Regression Results of Diversity Measures in Connecticut (2-digit) (Dependent variable in each equation is CVI)

\begin{tabular}{|c|c|c|c|c|c|c|c|c|}
\hline $\begin{array}{l}\text { Diversity Measure as } \\
\text { Independent Variable }\end{array}$ & $\overline{\text { Constant }}$ & $\begin{array}{l}\text { Estimats } \\
\text { Diversity } \\
\text { Index }\end{array}$ & d & $\begin{array}{l}\text { inuations } \\
\text { In(USMAI }\end{array}$ & & FIRES & \multicolumn{2}{|c|}{$\begin{array}{l}\text { Goodness } \\
\text { of Fit } \\
\mathbf{R}^{2} \text { D.W. }\end{array}$} \\
\hline $\begin{array}{l}\text { Equal distribution } \\
\text { (EDI) }\end{array}$ & $\begin{array}{l}-4.523 \\
(-1.53)\end{array}$ & $+\begin{array}{c}3.052 \\
(6.55)^{2}\end{array}$ & + & $\begin{array}{c}0.192 \\
(1.06)\end{array}$ & + & $\begin{array}{c}0.733 \\
(2.89)^{b}\end{array}$ & .801 & 1.301 \\
\hline $\begin{array}{l}\text { Entropy } \\
\text { (ENT) }\end{array}$ & $\begin{array}{c}0.147 \\
(0.05)\end{array}$ & $\begin{array}{r}11.263 \\
(7.56)^{2}\end{array}$ & + & $\begin{array}{l}0.252 \\
(1.58)\end{array}$ & + & $\begin{array}{c}0.622 \\
(2.80)^{b}\end{array}$ & .840 & 1.887 \\
\hline $\begin{array}{l}\text { National average } \\
\text { (NAI) }\end{array}$ & $\begin{array}{l}-19.297 \\
(-4.56)^{\mathrm{a}}\end{array}$ & $+\begin{array}{r}3.190 \\
(4.41)^{\mathrm{a}}\end{array}$ & + & $\begin{array}{c}1.107 \\
(4.47)^{2}\end{array}$ & + & $\begin{array}{l}0.134 \\
(0.43)\end{array}$ & .669 & 0.752 \\
\hline $\begin{array}{l}\text { Percent durables } \\
\text { (PD) }\end{array}$ & $\begin{array}{l}-2.445 \\
(-0.81)\end{array}$ & $+\begin{array}{c}4.438 \\
(6.65)^{2}\end{array}$ & - & $\begin{array}{r}0.049 \\
(-0.26)\end{array}$ & + & $\begin{array}{c}0.607 \\
(2.48)^{b}\end{array}$ & .805 & 1.946 \\
\hline $\begin{array}{l}\text { Consumers' durables } \\
\text { (CD) }\end{array}$ & $\begin{array}{l}-9.114 \\
(-1.43)\end{array}$ & $\begin{array}{r}1.523 \\
(0.26)\end{array}$ & + & $\begin{array}{c}0.539 \\
(1.36)\end{array}$ & + & $\begin{array}{r}0.277 \\
(0.52)\end{array}$ & .271 & 0.545 \\
\hline $\begin{array}{l}\text { Producers' durables } \\
\text { (PD) }\end{array}$ & $\begin{array}{l}-3.154 \\
(-1.23)\end{array}$ & $\begin{array}{r}4.952 \\
(8.06)^{2}\end{array}$ & - & $\begin{array}{r}9.080 \\
(-0.06)\end{array}$ & + & $\begin{array}{l}0.446 \\
(2.15)^{b}\end{array}$ & .856 & 1.991 \\
\hline $\begin{array}{l}\text { Portfolio variance } \\
\text { (PV) }\end{array}$ & $\begin{array}{l}-11.387 \\
(-6.40)^{2}\end{array}$ & $+\begin{array}{c}2.671 \\
(11.61)^{2}\end{array}$ & + & $\begin{array}{c}0.609 \\
(5.74)^{2}\end{array}$ & + & $\begin{array}{r}0.227 \\
(1.51)\end{array}$ & .922 & 2.438 \\
\hline
\end{tabular}

Note: $t$-statistics are in parentheses below coefficients. $R^{2}$ are adjusted values.

${ }_{\text {a }}$ Significant at .01 level

b Significant at .05 level

${ }^{\mathrm{c}}$ Significant at .10 level 
Most studies have explored the relationship between industrial diversity and stability at a 1-digit or 2-digit SIC level. Additional equations were estimated at the more common 2-digit level to see what impact the level of aggregation has on the ability of the measurements to explain cyclical instability. Each series was detrended in the manner described earlier, and the same steps were taken in calculating each index. The results are presented in Table 2. Relative to their counterpart estimates in Table 1, the estimates in Table 2 contain an improvement in the significance in each of the measures, the most noticeable of which are the national average and portfolio variance. It is not surprising that the equal distribution, national average, entropy, and various durables' measures perform better at the 2-digit level. The more aggregated level tends to mask its conceptual problems, while a more disaggregated level reveals them. Compared to those of their more traditional counterparts, statistical results suggest that the portfolio variance equations are relatively successful in tracking the cyclical variability index at either level of aggregation.

\section{TOWARD AN IMPROVEMENT IN REGIONAL POLICY}

New Directions: The question from a policymaker's point of view is how can such results, when based on an aggregate analysis, provide information to determine which industries they may encourage to expand in order to promote stability in state employment? ${ }^{8}$ Establishing policies to alter the shares of broadly defined industry groups provides little guidance when the cyclical behavior of the individual industries can vary from the aggregate, or when not based on the measurable characteristics of industries. In addition, it is unlikely, even if it is feasible, that regional policymakers would desire to adopt the economic structure of the national economy; that the cyclical pattern of their region is a mirror image of the national cycle seems an improbable outcome at any level of focus.

The one measure that may provide a basis for a diversification strategy for regions is the portfolio variance. What benefit can be derived from it and how can it become part of a strategy to assist policymakers in their efforts to reduce instability? As a starting place, it can identify industries that tend to promote stability in the state. The portfolio variance measures employment variability as a combination of weighted industry employment variances and the employment interaction between industries. An industry with a large own-variance may contribute significantly to regional instability, particularly if its share is sizable. However, despite its historical behavior, an industry's contribution to overall instability may be diminished, since zero or negative covariances with other industries will lessen its impact. The direction and magnitude of the interindustry 
relationships are identified in the computation of the portfolio variance. Since regional economies are not homogeneous in the types and magnitudes of the industries they possess or in interindustry production linkages, industries that promote stability in one region may tend to be destabilizing in another (see Conroy 1974).

Table 3 presents historical information on variance and countercyclical characteristics of industries in Connecticut. It ranks 81 state industries (41 shown) based on these two characteristics during the 1964-1983 interval. (Industry information is derived from the calculations of the portfolio variance in Equation 7.) Rankings are based on the number of zero and negative covariance terms an industry has with the remaining industries. The greater the number of zero and negative covariances an industry has with other industries, the greater its tendency to offset overall instability and the higher its ranking. There is a significant, positive correlation between ranking of all industries by zero and negative covariances and ranking by trend-adjusted historical variances (Spearman rank coefficient of 0.289 and $t=24.933$ ) as presented in the table. However, there is little correlation between ranking of industries based on the number of zero and negative covariances and unadjusted variances (Spearman rank correlation of -0.121 and t-stat of 9.765). While the spatial relationships between industries will impact the rankings and thus the statistical outcomes, such results do not suggest that regions promote the expansion of industries based on stability in their employment variances alone. It is necessary for policymakers to understand the cyclical interaction among industries in their regions in order to develop a strategy for reducing instability. Based on Table 3, such industries as periodicals (SIC 272), medical instruments and supplies (SIC 384), and nonmetallic mineral products (SIC 329) may be considered candidate industries because they promote cyclical stability in the state. ${ }^{9}$

Limitations: While the portfolio variance is significant in tracking the cyclical variability index, this measure alone cannot provide a feasible solution to the problem of reducing instability. The process of altering shares of industries in a region is complex and involves reallocating labor as well as financial and physical resources among industries. Industry shares in an industrial portfolio will change in a dynamic market economy, implying a certain degree of resource mobility and divisibility. However, other factors such as the spatial and economic characteristics of input and output markets, technological relationships among industries, environmental concerns, and the degree by which policymakers can realistically alter the composition of industries contribute to the complexity of this process; nevertheless, certain other considerations are necessary if any approach is to realistically address the problem of instability. ${ }^{10}$ 
TABLE 3

Ranking of Connecticut Industries by Variance and Covariance*

\begin{tabular}{|c|c|c|c|}
\hline $\begin{array}{l}\text { Covariance } \\
\text { Rank }\end{array}$ & $\begin{array}{c}\text { Variance } \\
\text { Rank }\end{array}$ & $\begin{array}{l}\text { SIC } \\
\text { Code } \\
\end{array}$ & $\begin{array}{c}\text { Industry } \\
\text { Description }\end{array}$ \\
\hline 1 & 13 & 272 & Periodicals \\
\hline 2 & 12 & 329 & Miscellaneous nonmetallic mineral products \\
\hline 3 & 34 & 394 & Toys and sporting goods \\
\hline 4 & 46 & 384 & Medical instruments and supplies \\
\hline 5 & 61 & 234 & Women's and children's undergarments \\
\hline 6 & 28 & 251 & Household furniture \\
\hline 7 & 53 & 238 & Miscellaneous apparel and accessories \\
\hline 8 & 5 & 229 & Miscellaneous textile goods \\
\hline 9 & 2 & 369 & Misc. electrical equipment and supplies \\
\hline 10 & 77 & 271 & Newspapers \\
\hline 11 & 50 & 264 & Converted paper products \\
\hline 12 & 7 & 391 & Jewelry, silverware, and plated ware \\
\hline 13 & 44 & 2799 & Other printing and publishing \\
\hline 14 & 45 & 3499 & Other fabricated metal products \\
\hline 15 & 58 & 205 & Bakery products \\
\hline 16 & 41 & 393 & Musical instruments \\
\hline 17 & 65 & 396 & Costume jewelry and notions \\
\hline 18 & 3 & 365 & Radio and TV receiving equipment \\
\hline 19 & 17 & 387 & Watches, clocks, and watchcases \\
\hline 20 & 26 & 3799 & Miscellaneous transportation equipment \\
\hline 61 & 22 & 3899 & Other instruments and related products \\
\hline 62 & 62 & 3599 & Other machinery-engines and turbines \\
\hline 63 & 43 & 239 & Miscellaneous fabricated textile products \\
\hline 64 & 15 & 3299 & Other stone, clay, and glass \\
\hline 65 & 60 & 331 & Blast furnace and basic steel products \\
\hline 66 & 69 & 364 & Electric lighting and wiring equipment \\
\hline 67 & 39 & 372 & Aircraft and parts \\
\hline 68 & 37 & 346 & Metal forgings and stampings \\
\hline 69 & 36 & 361 & Electric distributing equipment \\
\hline 70 & 56 & 345 & Screw machine products, bolts, etc. \\
\hline 71 & 80 & 202 & Dairy products \\
\hline 72 & 72 & 342 & Cutlery, hand tools, and hardware \\
\hline 73 & 67 & 356 & General industrial machinery \\
\hline 74 & 57 & 354 & Metalworking machinery \\
\hline 75 & 55 & 347 & Metal services \\
\hline 76 & 42 & 3399 & Other primary metal industries \\
\hline 77 & 52 & 31 & Leather \\
\hline 78 & 32 & 323 & Products of purchased glass \\
\hline 79 & 74 & 335 & Nonferrous rolling and drawing \\
\hline 80 & 38 & 336 & Nonferrous foundries \\
\hline 81 & 81 & 279 & Printing trade services \\
\hline
\end{tabular}

* Covariance ranking based on number of zero and negative covariances with remaining industries in descending order. Variance ranking based on size of industry variance. 
As a practical matter, it must also be recognized that stability in employment may be only one of several objectives of regional policymakers. For example, creating an economic environment to encourage general employment growth or maximizing tax revenues are often primary goals of state departments of economic development. However, policies to encourage growth in employment or tax revenues do not necessarily ensure stability in employment. While these policy issues are subject to discussion, establishing a goal of employment stability need not be inconsistent with such objectives. Whichever objectives are under consideration by policymakers, the cyclical behavior of industries within their region should have a bearing on policy and should be considered simultaneously with the remaining objectives. The list of candidate industries may be narrowed based on these additional objectives.

Final Comments: The approach taken in this study sheds light on a positive direction for reducing cyclical instability in regions. By focusing on the cyclical characteristics of detailed industries in a specific region, the possibility exists for developing policies to reduce overall instability. Policymakers' knowledge is not limited to general or subjective information based on broad classifications of industries from a number of variously defined regions. The portfolio variance provides an accurate measure of overall instability, information on the cyclical characteristics of individual industries, and a method to identify stability-promoting industries. While the focus could be broadened to include other industries, what is important is that we place our effort on developing a methodology for dealing pragmatically with the problem of regional instability.

\section{ENDNOTES}

1. For example, see McLaughlin (1930), Tress (1938), Rodgers (1957), Siegel (1966), Bahl, Firestine, and Phares (1971), Cutler and Hansz (1971), Conroy (1975), Barth, Craft, and West (1975), Hackbart (1975), Kort (1981), Jackson (1982), Brewer (1985), and Brewer and Moomaw $(1985,1986)$. Reviews of previous research approaches and findings are found in Conroy, Kort, Brewer, and Jackson.

2. A general knowledge of the behavior of a broadly defined group (a 1- or 2-digit level) is of limited practical value. A firm's cyclical employment behavior may differ not only from the broader group to which it belongs, but also from that of another firm in the same group. For example, from the group fabricated metal products (SIC 34), the industries of metal forgings and stampings (SIC 346) and fabricated metal products (SIC 342) exhibit great differences in historical employment variations at the national level between 1964 and 1983. SIC 346 exhibits 
wider fluctuations in employment than SIC 342 (based on historical variance as an absolute measure or coefficient of variation as a relative measure). Based on the coefficient of variation, SIC 346 exhibits nearly twice the variation as SIC 34, and SIC 342 exhibits about one-third less than SIC 34. Moreover, SIC 346 exhibits wider variation and SIC 342 exhibits less variation in employment relative to nearly all other 3-digit manufacturing industries. See Wundt (1988) for a more detailed analysis.

3. Only recently has attention been paid to development strategies for regions. For example, Conroy (1974) simulates sector changes in a cross section of MSAs to estimate the impact on stability; Cho and Schuermann (1980) simulate increases in overall employment in one MSA to estimate the change in employment levels and composition that minimize instability under various growth scenarios. Conroy focuses on a detailed 3-digit level but employs a national variance/covariance matrix, which assumes interindustry variations in each MSA are identical to those it the national level. In addition to incorporating nonmanufacturing sectors, Cho and Schuermann introduce input-output linkages as constraints, but their model is limited in a practical sense due to the aggregated focus.

4. A related, but more general, issue is that of selecting the state as the region of focus. It may be argued that regions within state boundaries, such as those with a dominant industry or with a concentration of cyclically unstable industries, could be targets for analysis. Connecticut presents an interesting case for study. First, it is dominated by two major defense-related industries, and second, certain regions within the state possess a greater concentration of these industries than others. However, what the state has witnessed is a rippling effect into other regions and industries due to the production interdependencies. Recent and forthcoming reductions in federal expenditures on defense have begun to impact employment in many of the state's defense-related manufacturing industries. Changing the regional focus masks the central issue of the defense dependency of the state. Furthermore, this problem is a widespread one and underscores the need for state and local policymakers to cooperate on such an issue.

5. Employment data for each industry class (twenty 2-digit and eighty-one 3digit) for Connecticut and the United States were obtained from County Business Patterns. Employment data in CBP are as reported in Treasury Form 941. Two potential concerns arise as a result of using this source. First, due to disclosure laws, state-level information for certain industries is not provided. Instead, a letter indicating a range of employment is given. Careful consideration of years of industry employment, coupled with the desire to maintain as much detail as possible, resulted in the choice of 81 industries. By definition, 3-digit industries sum to a 2-digit group. When industries within a 2-digit group were represented by a 
letter entry, they were treated as a residual (the 2-digit employment figure minus the remaining 3-digit industry employment). This approach is logical and does not require estimating industry employment. This problem is not present for significant or sizable industries in the state. Second, it could be argued that monthly or quarterly data could be used. It is not known whether an increased frequency would change the results significantly, contributing to our understanding and policymaking in this area. The changing presence of industries in a region is a gradual occurance. Moreover, in previous research that has employed monthly data, estimating industry employment was necessary (see Conroy 1975; Kort 1981; Brewer 1985; Brewer and Moomaw 1985), and thus the potential to produce contentious results exists.

6. A number of indices of regional economic variability and diversity have been developed. These indices are most often based on absolute or squared deviations from a trend or average (for example, see Bahl et al. 1971; Kort 1981; Jackson 1982). A comparison of the various indices has not been made, and it is likely that various index forms will impact the relationships being investigated.

7. For example, McLaughlin (1930) looked at the distinction between producers' goods and consumers' goods, which differs from the distinction between producer durables and consumer durables, since consumers' goods contain both durable and nondurable goods purchased by households. Siegel (1966) focused on total durables (producers' and consumers' combined) as did Borts (1961), Cutler and Hansz (1971), and Conroy (1975).

8. While it is beyond the immediate scope of this paper, there is a sizable literature on recruiting objectives and incentives of state and local governments. For example, see Katzman (1976), Loudon and Della Bitta (1976), Rasmussen et al. (1984), Miemyk (1980), Kale (1984), McHone (1984), and Marlin (1985) for research and evidence on recruiting and incentives. Despite the arguments to the contrary, state governments believe the effort to encourage the expansion of specific industries and general industrial recruitment provides an economic return to their region.

9. The notion that a region could benefit by expanding industries whose cyclical characteristics offset the general cyclical behavior of the region had been proposed by McLaughlin (1930) and Tress (1938). Unfortunately, more attention was paid to criticisms of such an approach (see Thompson 1956; Richardson 1969) than to developing a way to integrate this concept into a strategy, which was due in part to the lack of an appropriate technique to quantify the cyclical characteristics of industries, which the portfolio variance now provides. It was not until Markowitz (1952) developed his theory of portfolio diversification and Conroy (1975) adapted this method to the regional problem did this notion receive favorable attention. 
10. Additional information, such as technical relationships between industries, could be included in the analysis. Regional input-output table information may be added in the form of constraints, which would enable policymakers to evaluate the impact of specific or general industry expansions on the existing regional economy. For example, a model may be developed with the objective of minimizing the overall variance, subject to production-linkage constraints, or any number of additional constraints reflecting the region's preferences. See Cho and Schuermann (1980) and Wundt (1991).

\section{REFERENCES}

Bahl, Roy W., Robert Firestine, and Donald Phares. "Industrial Diversity in Urban Areas: Alternative Measures and Intermetropolitan Comparisions." Economic Geography 47 (1971): 414-25.

Barth, James, John Craft, and Phillip West. "A Portfolio Theoretic Approach to Industrial Diversification and Regional Employment." Journal of Regional Science 15 (1975): 9-15.

Borts, George H. "Regional Cycles of Manufacturing Employment in the United States, 1914-1953." National Bureau of Economic Research. Occasional Paper, no. 75, 1961.

Brewer, H. L. "Measures of Diversification: Predictors of Regional Economic Stability." Journal of Regional Science 25 (1985): 463-70.

Brewer, H. L., and Ronald L. Moomaw. "A Note on Population Size, Industrial Diversification, and Regional Economic Stability." Urban Studies 22 (1985): 349-354.

. "Regional Economic Instability and Industrial Diversification in the U.S.: Comment." Land Economics 62 (1986): 412-415.

Cho, Dong W., and Allen C. Schuermann. "A Decision Model for Regional Industrial Recruitment and Development." Regional Science and Urban Economics 10 (1980): 387-99.

Conroy, Michael E. "Alternative Strategies for Regional Industrial Diversification." Journal of Regional Science 14 (1974): 31-46.

"The Concept and Measurement of Regional Industrial Diversification." Southern Economic Journal 41 (1975): 492-505.

Cutler, Addison T., and James E. Hansz. "Sensitivity of Cities to Economic Fluctuations." Growth and Change 2 (1971): 23-28.

Hackbart, Merlin M., and Donald A. Anderson. "On Measuring Economic Diversification." Land Economics 51 (1975): 374-378. 
Jackson, Randall W. "An Evaluation of Alternative Measures of Regional Industrial Diversification." Regional Studies 18 (1982): 103-112.

Kale, Steven R. "U.S. Industrial Development Incentives and Manufacturing Growth during the 1970s." Growth and Change 15 (1984): 26-33.

Katzman, Martin T. "New Initiatives in State Economic Development Promotion: New England Prototypes." The Review of Regional Studies 6 (1976): 58-74.

Kort, John R. "Regional Economic Instability and Industrial Diversification in the U.S." Land Economics 57 (1981): 596-608.

Loudon, David L., and Albert J. Della Bitta. "State Activity in Industrial Development: The Southern New England Experience." The New England Journal of Business \& Economics 2 (1976): 58-79.

Markowitz, Harry. "Portfolio Selection." Journal of Finance 7 (1952): 77-91.

Marlin, Matthew R. "Evolution of a Subsidy: Industrial Revenue Bonds." Growth and Change 16 (1985): 30-35.

McHone, W. Warren. "State Industrial Development Incentives and Employment Growth in Multistate SMSAs." Growth and Change 15 (1984): 8-15.

McLaughlin, G. "Industrial Diversification in American Cities." Quarterly Journal of Economics 45 (1930): 131-49.

Miernyk, William H. "The Tools of Regional Development Policy." Growth and Change 11 (1980): 2-6.

Rasmussen, David W., Marc Bendick, Jr., and Larry C. Ledebur "A Methodology for Selecting Economic Development Incentives." Growth and Change 15 (1984): 18-25.

Richardson, Harry W. Regional Economics. New York: Praeger Publishers, 1969. Rodgers, Allen. "Some Aspects of Industrial Diversification in the United States." Economic Geography 33 (1957): 16-30.

Siegel, Richard A. "Do Regional Business Cycles Exist?" Western Economic Journal 5 (1966): 44-57.

Thompson, Wilbur. A Preface to Urban Economics. Baltimore: Johns Hopkins University Press, 1956.

Tress, R. C. "Unemployment and Diversification of Industry." The Manchester School 9 (1938): 140-52.

Wundt, Bruce D. "Industrial Diversification and Manufacturing Employment Stability: A Study of the State of Connecticut." Ph.D diss., Clark University, 1988.

"Minimizing Employment Instability: A Model of Industrial Expansion with Input-Output Considerations." Unpublished, 1991. 